\title{
Kinin $\mathrm{BI}$ and $\mathrm{B} 2$ receptor deficiency protects against obesity induced by a high-fat diet and improves glucose tolerance in mice
}

This article was published in the following Dove Press journal:

Diabetes, Metabolic Syndrome and Obesity: Targets and Therapy

26 August 2015

Number of times this article has been viewed

\author{
Rafael L Morais' \\ Elton D Silva' \\ Vicência M Sales' \\ Rafael Filippelli-Silva' \\ Marcelo A Mori' \\ Michael Bader ${ }^{2}$ \\ João B Pesquero'
}

'Department of Biophysics, Universidade Federal de São Paulo, São Paulo, Brazil; ${ }^{2}$ Max-Delbrück Center for Molecular Medicine, Berlin, Germany
Correspondence: João B Pesquero Department of Biophysics,

Universidade Federal de São Paulo, Pedro

de Toledo, 669 - 9th floor,

Vila Clementino 04039-034,

São Paulo, SP, Brazil

Tel +55 II 55764848 ext I2I4

Email jbpesquero@gmail.com

\begin{abstract}
The kallikrein-kinin system is well known for its role in pain and inflammation, and has been shown recently by our group to have a role also in the regulation of energy expenditure. We have demonstrated that $\mathrm{B} 1$ receptor knockout $(\mathrm{B} 1 \mathrm{KO})$ mice are resistant to obesity induced by a high-fat diet (HFD) and that B1 receptor expression in adipocytes regulates glucose tolerance and predisposition to obesity. However, it is also known that in the absence of B1 receptor, the B2 receptor is overexpressed and can take over the function of its B1 counterpart, rendering uncertain the role of each kinin receptor in these metabolic effects. Therefore, we investigated the impact of ablation of each kinin receptor on energy metabolism using double kinin receptor knockout (B1B2KO) mice. Our data show that B1B2KO mice were resistant to HFD-induced obesity, with lower food intake and feed efficiency when compared with wild-type mice. They also had lower blood insulin and leptin levels and higher glucose tolerance after treatment with an HFD. Gene expression for tumor necrosis factor-alpha and C-reactive protein, which are important genes for insulin resistance, was reduced in white adipose tissue, skeletal muscle, and the liver in B1B2KO mice after the HFD. In summary, our data show that disruption of kinin $\mathrm{B} 1$ and $\mathrm{B} 2$ receptors has a profound impact on metabolic homeostasis in mice, by improving glucose tolerance and preventing HFD-induced obesity. These novel findings could pave the way for development of new pharmacological strategies to treat metabolic disorders such as insulin resistance and obesity.
\end{abstract}

Keywords: kallikrein-kinin system, B1/B2 receptors, obesity, glucose tolerance, insulin resistance

\section{Introduction}

Obesity and diabetes are serious health problems that are of particular concern given their increasing incidence around the world. The World Health Organization estimates that at least 2.8 million people die each year as a result of being overweight or obese, and currently more than 1.4 billion adults are overweight. ${ }^{1}$ The excess energy intake in obese individuals is stored as fat tissue, which is an important organ in the regulation of metabolic homeostasis. ${ }^{2}$ In this scenario, obesity and diabetes are closely related since the accumulation of adipose tissue alters the pattern of secretion of molecules involved in physiological processes, such as glucose uptake, lipid metabolism, inflammation, and vascular homeostasis, ${ }^{3,4}$ which may lead to insulin resistance and development of diabetes.

Study of the kallikrein-kinin system (KKS) has contributed to our understanding of many biological processes, including inflammation, nociception, vascular permeability, blood pressure regulation, and smooth-muscle contraction and relaxation. ${ }^{5,6}$ 
The KKS consists of distinct enzymes called kallikreins, which cleave their precursors, kininogens, producing kinins, a small group of peptides. Kinins activate two specific G-protein coupled receptors, ie, B1 and B2. Although it has been known since 1932 that the KKS participates in energy metabolism, ${ }^{7}$ it has only been recently that these mechanisms have started to be elucidated. ${ }^{8,9}$ Several studies have highlighted the role of the B2 receptor in glucose homeostasis, in particular its effects on insulin-mediated glucose uptake. ${ }^{10,11}$ It was also shown that B1 receptor blockade by a specific antagonist could prevent hyperglycemia and insulitis, demonstrating that not only the $\mathrm{B} 2$ receptor but also the $\mathrm{B} 1$ receptor participates in the regulation of glucose uptake. ${ }^{12}$

More recently, the participation of the $\mathrm{B} 1$ receptor in insulin secretion has been demonstrated, ${ }^{13}$ as well as in the secretion of leptin by adipose tissue. ${ }^{14}$ More evidence concerning the role of $\mathrm{KKS}$ in metabolism came from $\mathrm{B} 1$ receptor knockout $(\mathrm{B} 1 \mathrm{KO})$ mice which were shown to be hypersensitive to leptin and resistant to obesity induced by a high-fat diet (HFD). ${ }^{15,16}$ Moreover, overexpression of the B1 receptor in adipocytes demonstrated that this receptor regulates glucose tolerance and determines predisposition to obesity. ${ }^{17}$ In agreement with these observations, recent findings have highlighted the inflammatory role of the B1 receptor in insulin-resistant glucose-fed rats, in which several pathological symptoms were reversed by treatment with specific B1 receptor antagonists. ${ }^{18,19}$

We can infer from the above data that KKS participates in development of obesity and related diseases, including insulin resistance and type 2 diabetes. However, the role played by each kinin receptor in these processes remains unclear, given the recurring evidence that in the absence of one receptor, the other is overexpressed and can compensate its functions. ${ }^{20,21}$

Therefore, we investigated energy metabolism in mice with deletion of both kinin receptors (B1B2KO). We found that B1B2KO mice had lower food and energy intake, lower feed efficiency, and lower serum insulin and leptin levels when compared with wild-type (WT) control mice. Hypothalamic mRNA expression of genes related to regulation of food intake and metabolism was unchanged in B1B2KO mice. However, when these mice were subjected to an HFD, they showed increased glucose tolerance when compared with their WT control littermates. The tumor necrosis factor-alpha (TNF- $\alpha$ ) and C-reactive protein (CRP) genes code for pro-inflammatory proteins that are also known for their role in insulin resistance, and show reduced mRNA expression in white adipose tissue, skeletal muscle, and the liver. These novel data suggest that B1 and B2 receptors have pivotal roles in energy balance by controlling glucose homeostasis and may be targets for insulin resistance and diabetes therapy.

\section{Materials and methods}

\section{Animals}

Healthy 12-week-old C57Bl/6 male B1B2KO mice and their WT littermates were used in this study. They were obtained from the animal house at Universidade Federal de São Paulo, São Paulo, and maintained on a 12-hour light/12-hour dark cycle at $22^{\circ} \mathrm{C}$, with free access to standard chow and drinking water. The experimental protocols were approved by the institutional ethics committee (01730/08).

\section{Genotyping of kinin BI and B2 knockout mice}

Genomic DNA was isolated from a mice tail fragment using an $\mathrm{NaOH}$ extraction protocol. ${ }^{22}$ Kinin B1 and B2 receptors were amplified by polymerase chain reaction (PCR) using the following primers: B1 receptor (NM_007539.2) sense 5'-TGAAGCTGTGAGCTCTTTG-3' and antisense 5'-GCTACCCAGATGAGCAGGCA-3'; B2 (NM_009747.2) receptor sense 5'-TGTCCTCAGCGTGTTCTTCC-3' and antisense 5'-GGTCCTGAACACCAACATGG-3'.

\section{Kinin $B 1$ and $B 2$ receptor function}

The functionality of B1 and B2 receptors was assayed by testing the contractile response of smooth muscle strips (from the fundus of the stomach) to bradykinin and des-Arg(9)-bradykinin (Bachem Inc.). Briefly, smooth muscle strips were extracted from the mice and kept at $37^{\circ} \mathrm{C}$ in oxygenated $\left(95 \% \mathrm{O}_{2}, 5 \%\right.$ $\mathrm{CO}_{2}$ ) modified Krebs buffer (119 NaCl mM, $4.7 \mathrm{KCl} \mathrm{mM}, 1.2$ $\mathrm{MgSO}_{4}: 7 \mathrm{H}_{2} \mathrm{O} \mathrm{mM}, 2.5 \mathrm{CaCl}_{2}: 2 \mathrm{H}_{2} \mathrm{O} \mathrm{mM}, 1.2 \mathrm{KH}_{2} \mathrm{PO}_{4} \mathrm{mM}$, $25.0 \mathrm{NaHCO}_{3} \mathrm{mM}$, and 5.5 glucose $\mathrm{mM}$ ). After an equilibration period of 45-60 minutes at a resting tension of $0.5 \mathrm{~g}$, experiments were initiated by checking the viability of the prepared specimen by exposure to carbachol (Sigma-Aldrich) at $10^{-5}$ M. Kinin agonists, ie, bradykinin $10^{-6} \mathrm{M}$ and Des-Arg(9)bradykinin, $10^{-6} \mathrm{M}$ ), were then applied, and the contractile responses were recorded using an isometric transducer (TRI202P, Panlab) connected to a computerized system for data acquisition and analysis (PowerLab, AD Instruments).

\section{Treatment with a high-fat diet}

Mice were fed ad libitum for 12 weeks with a control diet (10\% kcal from fat) or an HFD (45\% kcal from fat) from Research Diets Inc. Each mouse was put in an individual cage, with weekly weight and food intake recording. 
After treatment, the mice were euthanized for blood and tissue collection. Feed efficiency was calculated by the ratio of total weight gain and calories of food ingested in both WT and B1B2KO mice after treatment with the HFD.

\section{Leptin and insulin serum levels}

Serum samples were separated and used for leptin (R\&D Systems) and insulin (Millipore) measurement as specified by the manufacturers.

\section{Glucose tolerance test}

Mice were fasted for 8 hours before the glucose tolerance test. A small fragment of tail tissue was cut for blood collection and glucose was quantified using an Advantage II glucometer (Roche). Glucose measurements were carried out before and at $15,30,60$, and 120 minutes after intraperitoneal injection of glucose $1 \mathrm{~g} / \mathrm{kg}$ body weight.

\section{Insulin and leptin sensitivity test}

For the insulin sensitivity test, $0.01 \mathrm{U} / \mathrm{kg}$ of recombinant human insulin (Lilly) was injected intraperitoneally. Glucose levels were assessed in blood collected from the tail before and 15,30 , and 60 minutes after insulin injection immediately after treatment with the HFD. For leptin sensitivity, recombinant mouse leptin (R\&D Systems) was injected as an intraperitoneal bolus of $40 \mu \mathrm{g} /$ day for 5 days, with food intake measured under basal conditions. Food intake measured 5 days before the leptin injections was considered as basal consumption.

\section{Gene expression}

Total RNA $(2 \mu \mathrm{g})$ was extracted from the hypothalamus, white adipose tissue, skeletal muscle, and liver from WT and B1B2KO mice using TRIzol Reagent (Invitrogen). It was reversetranscribed using M-MLV (Invitrogen) to cDNA following the manufacturer's instructions. The product was amplified by real-time PCR using the SYBR Green (Fermentas) protocol. Prolylcarboxipeptidase (PRCP), melanocortin 4 receptor (MC4R), neuropeptide Y (NPY), agouti-gene-related protein (AgRP), pro-opiomelanocortin (POMC), cocaineand amphetamine-regulated transcript (CART), leptin, TNF- $\alpha$, and CRP mRNAs were quantified as a relative value compared with the internal reference, $\beta$-actin. Primers used for real-time PCR were as follows: PRCP (NM_001278581.1) sense 5'-CAGGAGCTCAAGGTCAACCTGTC-3' and antisense 5'-GAACCATACCATCAAGCT GCCAGAT-3'; MC4R (NM_016977.4) sense 5'-GCTGTGGCAGATATGCTGGTGAG-3' and antisense 5'-CGAGCAAGGAGCTACAGATCACAG-3'; NPY
(NM_023456.2) sense 5'-CGCTCTGCGACACTACAT CAA-3' and antisense 5'-GGGCTGGATCTCTTGCCAT-3'; AgRP(NM_001271806.1) sense 5'-GGTGCTAGATC CACA GAACCG-3' and antisense 5'-CCAAGCAGGACTCGT GCAG-3'; POMC (NM_001278581.1) sense 5'-CGAGGCCTTTCCCCTAGAGT-3' and antisense 5'-CCAGGACTTGCTCCAAGCC-3'; CART (NM_013732.7) sense 5'-TGGATGATGCGTCCCATGA-3' and antisense 5'-CGGAATGCGTTTACTCTTGAGC-3'; leptin (NM_008493.3) sense 5'-AGCATTCAGG GCTAACATCC-3' and antisense 5'-TATCCGCCA AGCAGAGGGT-3'; TNF- $\alpha$ (NM_013693.3) sense 5'-CACCACGCTCTTCTGTCTAC-3' and antisense 5'-GA TCTGAGTGTGAGGGTCTGG-3'; CRP (NM_007768.4) sense 5'-GGAGAAGCTACTCTGGTGCCTTCT-3' and antisense 5'-CACACAGTAAAGGTGTTCAGTGGCT-3', and $\beta$-actin (NM_007393.3) sense 5'- GAACCCTAAGGC CAACCGTGAA-3' and antisense 5'- GACCAGAGGCAT ACAGGGACAAC-3'. Quantitative values for mRNA expression were obtained by the parameter $2^{-\Delta \mathrm{Ct}}$, in which $\Delta \mathrm{Ct}$ represents the subtraction of the $\beta$-actin $\mathrm{Ct}$ values from the ones of the target gene.

\section{Treatment with kinin $\mathrm{BI}$ and $\mathrm{B} 2$ receptor antagonists}

Healthy 12-week-old male $\mathrm{C} 57 \mathrm{Bl} / 6$ mice were injected intraperitoneally daily for 7 days with the $\mathrm{B} 1$ receptor antagonist $\mathrm{R}-715(1 \mathrm{mg} / \mathrm{kg})$ together with the $\mathrm{B} 2$ receptor antagonist HOE-140 $(500 \mu \mathrm{g} / \mathrm{kg})$ or vehicle (saline). Both antagonists were obtained from Bachem Inc. After treatment, the mice in both groups were euthanized and their tissues collected for analysis of leptin, CRP, and TNF- $\alpha$ gene expression.

\section{Statistical analysis}

The results are reported as the mean \pm standard error of the mean. Statistically significant differences in mean values were evaluated by the independent Student's t-test when two groups were compared, or by the ANOVA test when three or more groups were analyzed. A $P$-value $\leq 0.05$ was considered to be statistically significant.

\section{Results \\ Genetic and pharmacological assays for kinin $\mathrm{BI}$ and $\mathrm{B} 2$ receptors}

Deletion of both kinin receptors in the mice was confirmed by PCR genotyping, as demonstrated in Figure 1. In the DNA samples from WT mice, B1 (Figure 1A) and B2 receptor (Figure 1B) gene fragments were amplified by PCR, whereas 
A

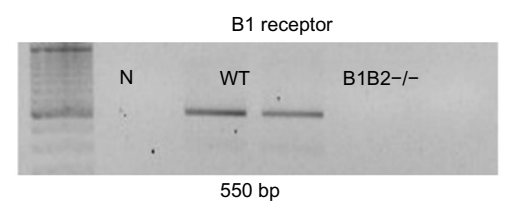

C

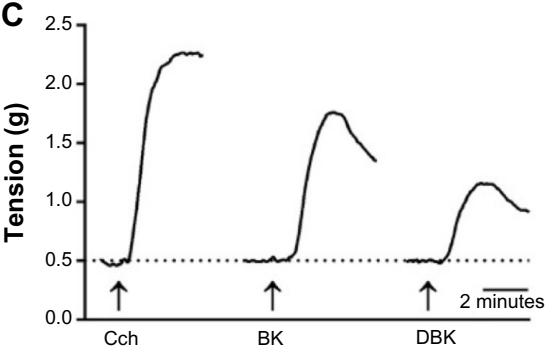

B

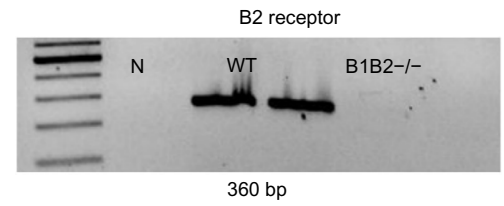

D 25

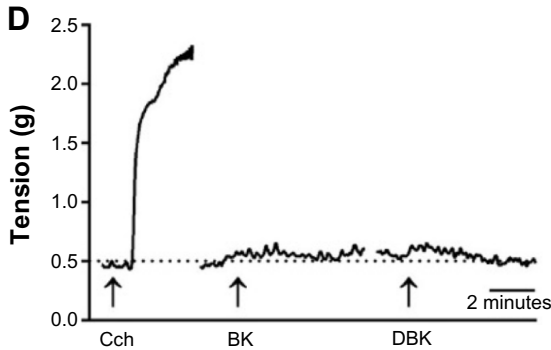

Figure I Genotyping the kinin $\mathrm{BI}$ and $\mathrm{B} 2$ receptor in $\mathrm{BIB} 2 \mathrm{KO}$ mice.

Notes: $(\mathrm{A}) \mathrm{BI}$ and (B) B2 receptor gene fragments were amplified by polymerase chain reaction. The contractile response of smooth muscle strips from the gastric fundus to Cch (positive control), BK, and DBK in (C) WT and (D) BIB2KO mice.

Abbreviations: BK, bradykinin; DBK, des-Arg(9)-bradykinin; N, negative control; WT, wild-type; BIB2-l-, BIB2KO; Cch, carbachol.

in B1B2KO mice the fragments could not be amplified. The pharmacological functionality of the B1 and B2 receptors was assayed by testing the contractile response of smooth muscle strips from the gastric fundus to bradykinin and desArg(9)-bradykinin. WT mice preparations were responsive to carbachol and to B1 and B2 receptor agonists (Figure 1C). On the other hand, double knockout mice were responsive to carbachol but not to the kinins (Figure 1D), confirming the absence of $\mathrm{B} 1$ and $\mathrm{B} 2$ receptors in this genetic mouse model.

\section{BIB2KO mice protected against HFD-induced obesity}

Body weight was measured for 12 weeks in B1B2KO mice on a control diet or the HFD. The mice had a reduced body weight and smaller visceral fat depots after the HFD but not after the control diet (Figure 2A and B). To investigate why $\mathrm{B} 1 \mathrm{~B} 2 \mathrm{KO}$ mice were protected against HFD-induced weight gain, food and energy intake was measured every week during the HFD and chow diet regimen. As shown in Figure $2 \mathrm{C}$ and D, WT mice showed higher food intake and calories ingested when compared with B1B2KO mice regardless of the type of diet. Also, the B1B2KO mice on the HFD showed lower feeding efficiency (Figure 2E), indicating more energy expenditure after the HFD.

\section{Gene expression in the hypothalamus was unchanged in BIB2KO mice}

Given the reduced food and energy intake found in the B1B2KO mice, we also investigated the mRNA expression of important hypothalamic genes associated with satiety and energy balance. However, expression of orexigenic (NPY, AgRP), anorexigenic
(POMC, CART), PRCP, and MC4R genes was not significantly different between B1B2KO and WT mice treated with a control diet or the HFD (data not shown).

\section{Insulin and leptin levels were reduced in $\mathrm{BIB} 2 \mathrm{KO}$ mice}

In order to better understand the metabolic profile in $\mathrm{B} 1 \mathrm{~B} 2 \mathrm{KO}$ mice, we measured two important hormones involved in energy homeostasis, ie, insulin and leptin. Insulin and leptin levels (protein in the serum and mRNA from white adipose tissue) were decreased in B1B2KO mice when compared with WT mice using both regimens (Figure $3 \mathrm{~A}-\mathrm{C}$ ). No difference in leptin sensitivity was observed in $\mathrm{B} 1 \mathrm{~B} 2 \mathrm{KO}$ mice after the HFD (Figure 3D). Also, B1B2KO mice on the control diet or HFD did not present changes in insulin sensitivity when compared with WT mice (Figure 3E).

\section{BIB2KO mice showed improved glucose tolerance}

Differences in insulin levels between B1B2KO and WT mice suggested a potential impact of the $\mathrm{B} 1$ and $\mathrm{B} 2$ receptors on blood glucose levels and glucose tolerance. B1B2KO mice showed lower glucose levels than WT mice after treatment with the HFD (Figure 4A). Accordingly, in this condition, B1B2KO mice also showed higher glucose tolerance after glucose stimulation (Figure 4B).

\section{Genes related to insulin resistance were downregulated after HFD}

Given the importance of inflammation in the pathogenesis of insulin resistance, we measured the expression of two inflammatory mediators in different metabolic tissues of 
A

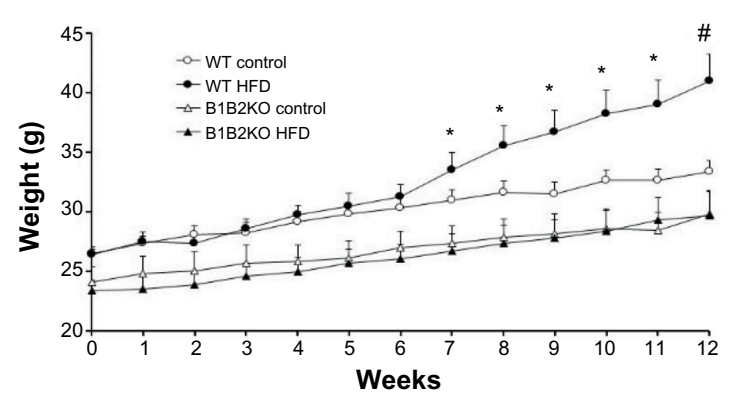

C

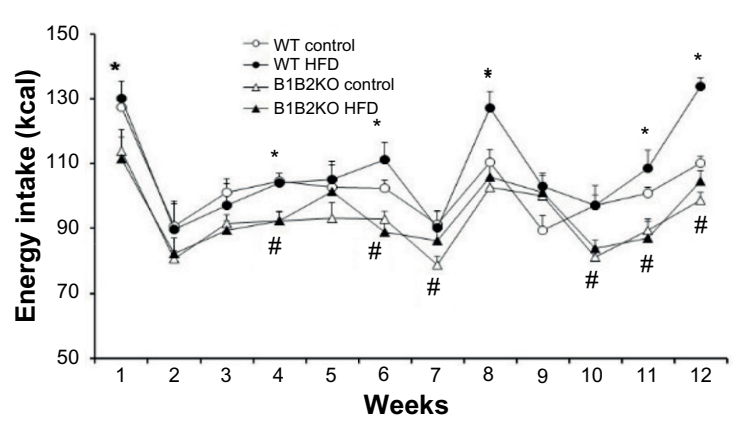

B

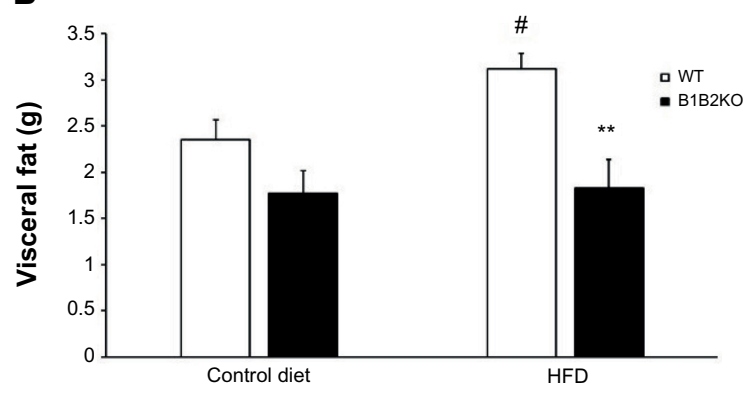

D

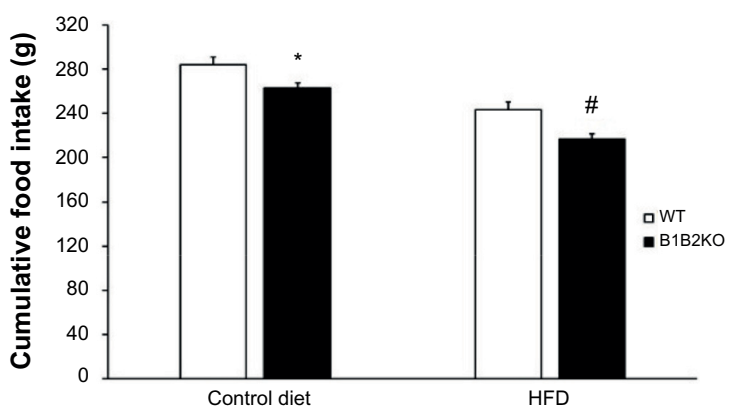

E

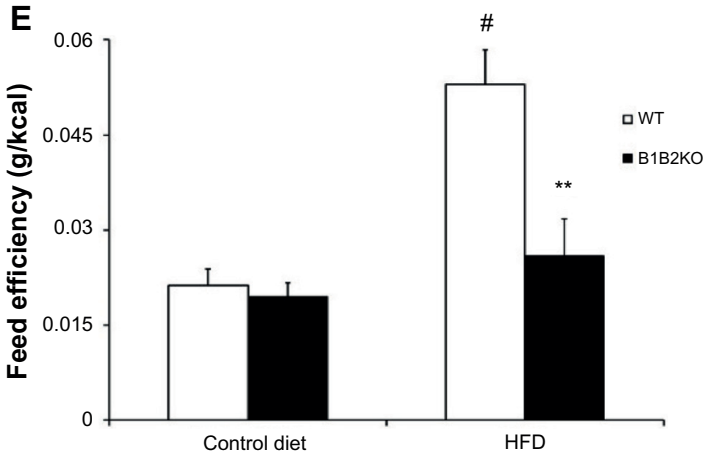

Figure 2 BIB2KO mice are protected against obesity induced by HFD treatment and present lower food intake and feed efficiency.

Notes: (A) Body weight after 12 weeks of HFD treatment. ${ }^{* P}<0.05$ WT HFD versus BIB2KO groups; ${ }^{*} P<0.05$ versus all groups. Data are expressed as the mean \pm standard error of the mean and represent mouse weight per gram. White circles indicate WT control, black circles indicate WT HFD, white triangles indicate BIB2KO control, and black triangles indicate BIB2KO HFD. (B) Visceral fat weight after 12 weeks of HFD treatment. White bars indicate WT control and HFD, and black bars indicate BIB2KO control and HFD. ${ }^{P}<0.05$ WT HFD versus WT control; $* * P<0.01$ WT HFD versus BIB2KO HFD. Data are expressed as the mean \pm standard error of the mean and represent visceral fat depot weight per gram. (C) Energy intake after 12 weeks of HFD treatment. Energy intake was calculated based on information from the chow manufacturer. White circles indicate WT control, black circles indicate WT HFD, white triangles indicate BIB2KO control, and black triangles indicate BIB2KO HFD. $* P<0.05$ WT HFD versus BIB2KO HFD; ${ }^{P}<<0.05 \mathrm{WT}$ control versus BIB2KO control. Data are expressed as the mean \pm standard error of the mean and represent energy intake (kCal). (D) Cumulative food intake after 12 weeks of HFD treatment. White bars indicate WT control and HFD, black bars indicate BIB2KO control and HFD. $* P<0.05$ WT control versus BIB2KO control; ${ }^{*} P<0.05$ WT HFD versus BIB2KO HFD. Data are expressed as the mean \pm standard error of the mean and represent chow per gram. (E) Feed efficiency after 12 weeks of HFD treatment. Feed efficiency was calculated by the ratio of total weight gain and calories of food ingested after the HFD treatment in both WT and BIB2KO mice. White bars indicate WT control and HFD, black bars indicate BIB2KO control and HFD. P $<0.0 \mathrm{I}$ WT HFD versus control diet group. ${ }^{* * P}<0.01$ WT HFD versus BIB2KO HFD. Data are expressed as the mean \pm standard error of the mean and represent energy intake ( $\mathrm{kCal}$ ).

Abbreviations: HFD, high-fat diet; WT, wild-type.

double knockout mice. TNF- $\alpha$ mRNA expression was reduced in both white adipose tissue and skeletal muscle in B1B2KO mice after the HFD (Figure 5A and B). Similarly, CRP mRNA expression was decreased in the livers of the B1B2KO mice after the HFD (Figure 5C). In addition, WT mice were treated for 7 days with specific B1 (R-715) and B2 (HOE-140) receptor antagonists. Gene expression of leptin and TNF- $\alpha$ in white adipose tissue and skeletal muscle was measured and CRP expression was evaluated in the liver, but no differences were observed (data not shown).

\section{Discussion}

Using both genetic and pharmacological approaches, the role of kinin receptors in energy balance has started to be elucidated in recent years. However, it is known that when one of the kinin receptors is blocked or deleted, the other receptor 

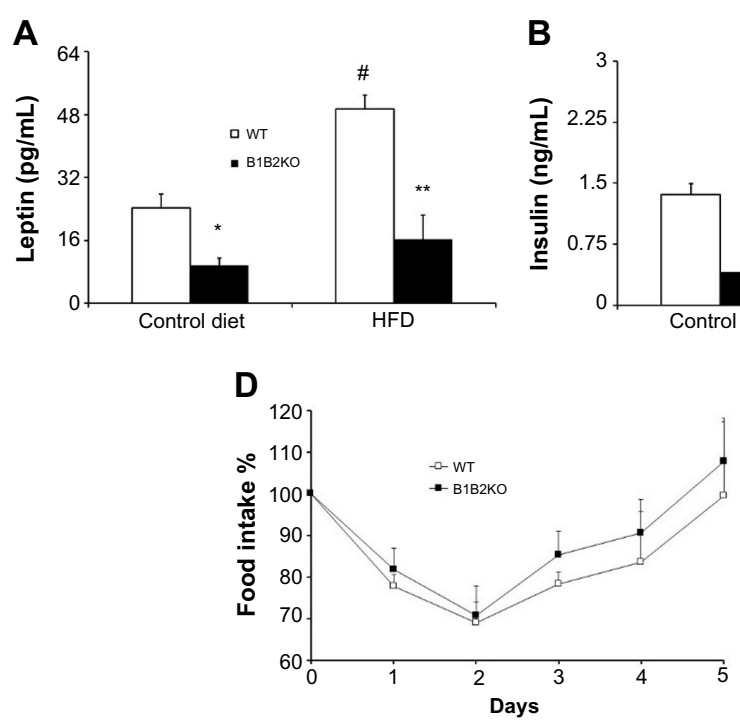
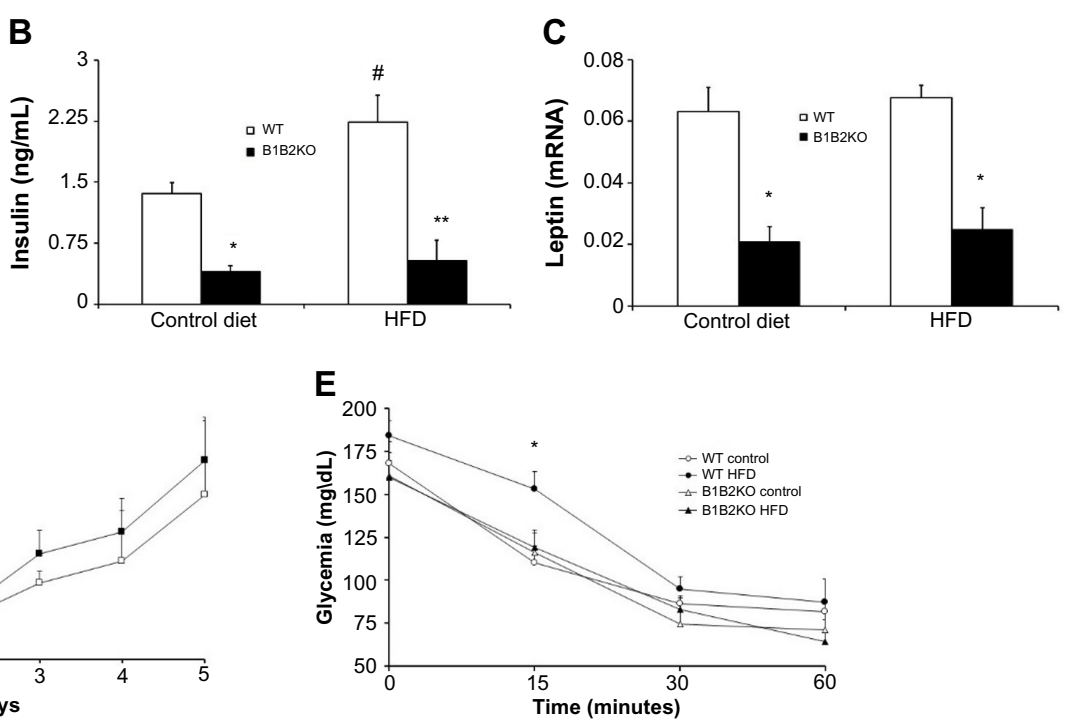

Figure 3 BIB2KO mice have low insulin and leptin levels.

Notes: (A) Serum leptin levels after 12 weeks of HFD treatment. (B) Serum insulin levels after 12 weeks of HFD treatment. (C) Leptin mRNA expression in white adipose tissue after 12 weeks of HFD treatment. White bars indicate WT control and HFD, and black bars indicate BIB2KO control and HFD. $* P<0.05$ BIB2KO control versus WT control; ${ }^{* * P}<0.0$ I BIB2KO HFD versus WT HFD; ${ }^{*} P<0.05$ WT HFD versus WT control. (D) Leptin sensitivity test in WT and BIB2KO mice. Consumption was measured after intraperitoneal injection of $40 \mu \mathrm{g} /$ day of leptin and compared with basal consumption. Data are expressed as the mean \pm standard error of the mean and represent percentage of food intake. White squares indicate WT, black squares indicate BIB2KO. (E) Insulin sensitivity test after 12 weeks of HFD treatment. Glycemia was measured before and after intraperitoneal injection of insulin $0.01 \mathrm{U} / \mathrm{kg}$ at following the times: $0,15,30$, and 60 minutes. Data are expressed as the mean \pm standard error of the mean. White circles indicate WT control, black circles indicate WT HFD, white triangles indicate BIB2KO control, and black triangles indicate BIB2KO HFD. *P $<0.05$ WT HFD versus all groups.

Abbreviations: HFD, high-fat diet; WT, wild-type.

may compensate by upregulating its expression, which may introduce a confounding factor when interpreting data. To resolve part of this issue, $\mathrm{B} 1 \mathrm{~B} 2 \mathrm{KO}$ mice were generated and characterized. These double knockout mice are healthy, fertile, normotensive, and protected against endotoxininduced hypotension. ${ }^{23}$

In our present work, we have shown that $\mathrm{B} 1 \mathrm{~B} 2 \mathrm{KO}$ mice are resistant to HFD-induced obesity, showing less food intake and a smaller weight gain per calorie intake when compared with WT mice. Based on these observations, we analyzed the
mRNA expression of genes in the hypothalamus associated with metabolism. NPY and AgRP, both orexigenic genes, were found to be present at the same levels in B1B2KO and WT mice whether on the control diet or the HFD. Similarly, expression of anorexigenic genes, POMC and CART, was not different between knockout and control mice. Recently, our group found that CART mRNA expression is elevated in the lateral hypothalamic area of B1KO mice. ${ }^{24}$ Even though $\mathrm{B} 1 \mathrm{KO}$ and $\mathrm{B} 1 \mathrm{~B} 2 \mathrm{KO}$ mice show similarities in some aspects of metabolism, expression of CART seems to be different in
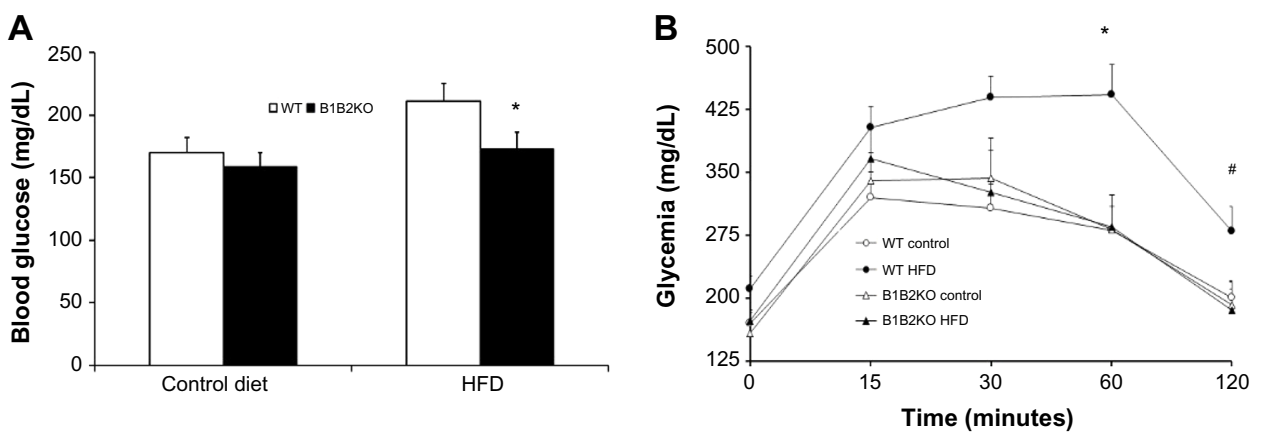

Figure 4 BIB2KO mice show high glucose tolerance.

Notes: (A) Glucose levels after 12 weeks of HFD treatment. White bars indicate WT control and HFD, black bars indicate BIB2KO control and HFD. *P $<0.05$ WT HFD versus BIB2KO HFD. (B) Glucose tolerance test after I2 weeks of HFD treatment. Glycemia was measured before and after intraperitoneal injection of glucose I g/kg at the following times: $0,15,30,60$, and 120 minutes. Data are expressed as the mean \pm standard error of the mean. White circles indicate WT control, black circles indicate WT HFD, white triangles indicate BIB2KO control, and black triangles indicate BIB2KO HFD. ${ }^{*} P<0.05$ WT HFD versus all groups and $\#$ P $<0.05$ WT HFD versus BIB2KO HFD. Abbreviations: HFD, high-fat diet; WT, wild-type. 
A

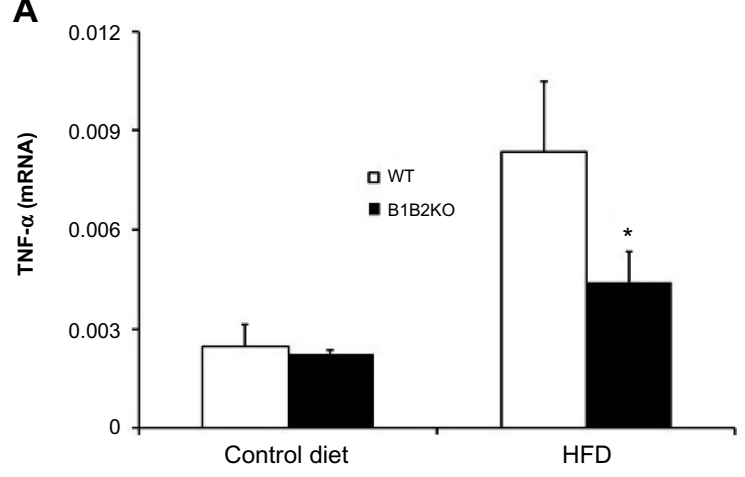

B

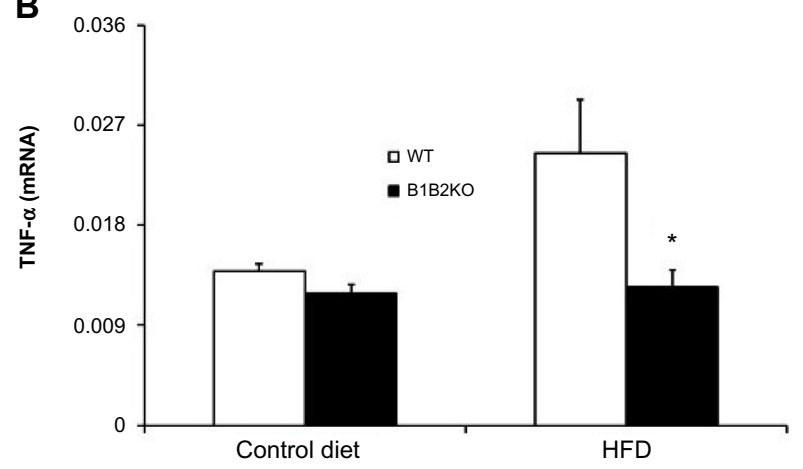

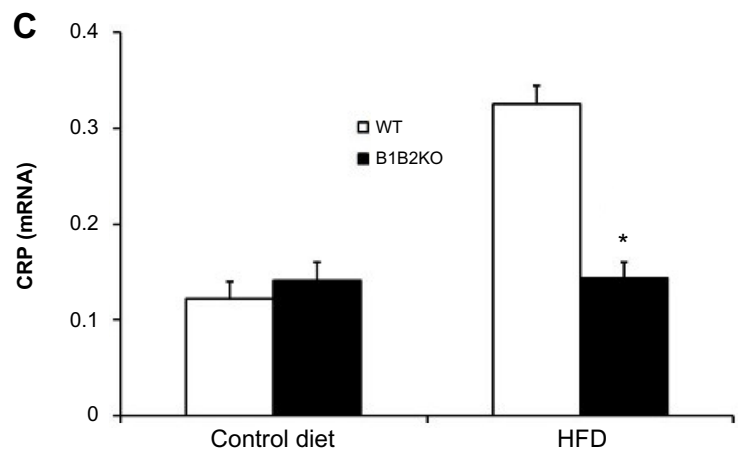

Figure 5 Inflammatory cytokines are downregulated in tissues of BIB2KO mice.

Notes: TNF- $\alpha$ mRNA expression in white adipose tissue (A) and skeletal muscle tissue (B) after 12 weeks of HFD treatment. (C) CRP mRNA expression in the liver after 12 weeks of HFD treatment. Data are expressed as the mean \pm standard error of the mean of the $2^{-\Delta C t}$ parameter and represent the relative expression between TNF- $\alpha / C R P$ and $\beta$-actin. White bars indicate WT control and HFD, black bars indicate BIB2KO control and HFD. $* P<0.05$ BIB2KO HFD versus WT HFD.

Abbreviations: HFD, high-fat diet; WT, wild-type; CRP, C-reactive protein; TNF- $\alpha$, tumor necrosis factor-alpha.

the two strains. However, it should be taken into account that we analyzed expression of CART in the whole hypothalamus of B1B2KO mice, and not only in the lateral hypothalamic area, which may have contributed to the observed lack of differences. Further, Heijboer et al demonstrated that gene expression for NPY, AgRP, POMC, and CART is not altered in the mouse hypothalamus after treatment with an HFD, ${ }^{25}$ suggesting that regulation of these genes may be not affected by an HFD in WT or B1B2KO mice. PRCP and MC4R gene expression was also tested, given the role of these genes in metabolism. PRCP is an enzyme associated with inactivation of alpha-melanocortin-stimulating hormone in rodents, ${ }^{26}$ which in turn binds to MC4R to regulate food intake behavior and energy balance. ${ }^{27}$ Together with other orexigenic and anorexigenic genes, expression of PRCP and MC4R was unchanged in the B1B2KO mouse hypothalamus after treatment with the control diet or the HFD, indicating that the reduced food consumption observed in these mice was probably related to an alternative metabolic pathway not examined in this study.

Circulating levels of leptin and insulin were also measured in the B1B2KO and WT mice. Decreased serum levels of both hormones were found in the double knockout mice on the control diet or the HFD. These data suggest hypersensitivity to these hormones, although no changes in insulin and leptin sensitivity were observed in B1B2KO mice. On the other hand, B1B2KO mice showed less glycemia and increased glucose tolerance after treatment with the HFD. We believe the mechanisms underlying these findings may be related to the control of energy intake and its expenditure. Indeed, energy expenditure is increased in B1B2KO mice, as suggested by the feed efficiency data. Studies analyzing the impact of B1 receptor on metabolism have found that $\mathrm{B} 1 \mathrm{KO}$ mice benefit from deletion of the B1 receptor, with better leptin and insulin sensitivity. ${ }^{16,17}$ In agreement with this, blockade of the B1 receptor by the specific inhibitor SSR240612 reverted insulin and glucose concentrations to baseline levels in insulin-resistant glucose-fed rats. ${ }^{19}$

By analyzing the $\mathrm{B} 2$ receptor knockout (B2KO) mouse phenotype, our group has found decreased serum insulin levels and increased glucose uptake after stimulation with insulin (unpublished data). Schweitzer et $\mathrm{al}^{28}$ reported that $\mathrm{B} 2 \mathrm{KO}$ mice also have lower serum insulin levels, but show decreased glucose tolerance. Conversely, it has been shown that B2KO mice have higher serum insulin levels and are resistant to the effects of insulin on mediating glucose uptake. ${ }^{29}$ Taking 
these data together, the role of the B2 receptor in glucose uptake remains controversial. We can conclude that disruption of this receptor leads to significant alterations in glucose homeostasis, probably by compensatory mechanisms promoted by other related genes. Indeed, recent gene expression data from microarray analysis of B2KO mice have shown dysregulation of several genes related to pathological pathways involved in endothelial injury, oxidative stress, insulin and leptin metabolism, and the inflammatory process. ${ }^{30}$ Therefore, we propose that deletion of the $\mathrm{B} 2$ receptor in mice regulates expression of not only the $\mathrm{B} 1$ receptor ${ }^{20}$ but also genes linked to insulin and glucose homeostasis. In agreement with this idea, we believe that disruption of the B1 receptor in mice leads not only to altered expression of B2 receptor, ${ }^{21}$ but also other genes related to control of the energy balance. In this scenario, our double knockout model shows that metabolic parameters measured in the B1B2KO mice were not exclusively dependent on $\mathrm{B} 1$ or $\mathrm{B} 2$ receptor regulation, indicating that ablation of the $\mathrm{B} 1$ and/or $\mathrm{B} 2$ receptor might also have a profound impact on several other gene pathways related to disorders of metabolism.

To determine the link between abrogation of KKS and genes involved in metabolic homeostasis, we analyzed gene expression of proteins related to insulin resistance and the inflammatory process. We focused on inflammatory genes because the B1 receptor plays an important role in the immune response in many disorders. ${ }^{31-33}$ Thus, we measured gene expression of TNF- $\alpha$ and CRP, given that these proteins are present in elevated concentrations in insulin-resistant and obese individuals. In these cases, white adipose tissue and skeletal muscle are the main sources of TNF- $\alpha,{ }^{34,35}$ which is directly related to impaired glucose uptake and insulin resistance mechanisms via activation of nuclear factor kappa B and IKK $\beta$ signaling. ${ }^{36}$ Here we found that B1B2KO HFD-treated mice had decreased TNF- $\alpha$ mRNA expression in white adipose tissue and skeletal muscle. Similarly, increased CRP levels, with liver as the main source, are related to impaired insulin resistance. ${ }^{16} \mathrm{We}$ observed that CRP mRNA expression was decreased in the liver of the B1B2KO mouse after the HFD. Recently, Diaz et al demonstrated that blockade of the B1 receptor is able to reverse inflammatory biomarkers related to insulin resistance in insulin-resistant glucose-fed rats. ${ }^{19}$ These findings suggest that reduced mRNA expression of TNF- $\alpha$ and CRP could be related to deletion of the $\mathrm{B} 1$ receptor in $\mathrm{B} 1 \mathrm{~B} 2 \mathrm{KO}$ mice. Absence of the proinflammatory $\mathrm{B} 1$ receptor could be mandatory to modify the expression of inflammatory genes involved in the pathology of insulin resistance.
Accordingly, in order to observe the effect of pharmacological blockade of the B1 and B2 receptors, we treated WT animals with specific antagonists, ie, R-715 and HOE-140. No change in mRNA expression was observed after pharmacological treatment for leptin, TNF- $\alpha$, and CRP gene expression in white adipose tissue, skeletal muscle, or the liver. Conversely, leptin mRNA expression was not decreased in white adipose tissue after treatment with specific antagonists, indicating that the decreased baseline leptin levels found in B1B2KO mice probably resulted from more profound and prolonged inactivation of kinin receptors.

In conclusion, we found that a deficiency of B1 and B2 receptors protects against obesity induced by an HFD and promotes a decrease in circulating levels of insulin and leptin. In addition, deletion of both $\mathrm{B} 1$ and $\mathrm{B} 2$ receptors has specific consequences with regard to mechanisms involving glucose homeostasis, ie, improving glucose tolerance. We propose that compensatory effects, as a consequence of disruption of the KKS, could dysregulate expression of inflammatory genes related to metabolic disorders such as insulin resistance. Therefore, our findings reinforce the role of the KKS in metabolism by showing that $\mathrm{B} 1$ and $\mathrm{B} 2$ receptor regulation is crucial for glucose tolerance control in mice, and suggest that new drugs focused on the KKS might be effective as therapeutic tools for conditions related to obesity, such as insulin resistance and diabetes.

\section{Acknowledgments}

We are grateful to our laboratory technicians Juliana Gilbert and Emanoel Barreto for helping with the experiments and to Dr Renan Paulo Martin for assistance with the graphical design.

This work was supported by Fundação de Amparo a Pesquisa do Estado de São Paulo, Conselho Nacional de Desenvolvimento Científico e Tecnológico, and Coordenação de Aperfeiçoamento de Pessoal de Nível Superior.

\section{Disclosure}

The authors report no conflicts of interest in this work.

\section{References}

1. World Health Organization. Global Health Observatory (GHO) data, risk factors. Available from: http://www.who.int/gho/ncd/risk_factors/ obesity_text/en/. Accessed August 12, 2015.

2. Waki H, Tontonoz P. Endocrine functions of adipose tissue. Annu Rev Pathol. 2007;2:31-56.

3. Arner P. The adipocyte in insulin resistance: key molecules and the impact of the thiazolidinediones. Trends Endocrinol Metab. 2003;14: $137-145$.

4. Tilg H, Moschen AR. Adipocytokines: mediators linking adipose tissue, inflammation and immunity. Nat Rev Immunol. 2006;6:772-783. 
5. Bhoola KD, Figueroa CD, Worthy K. Bioregulation of kinins: kallikreins, kininogens, and kininases. Pharmacol Rev. 1992;44:1-80.

6. Regoli D, Barabe J. Pharmacology of bradykinin and related kinins. Pharmacol Rev. 1980;32:1-46.

7. Frey EK, Kraut H, Werle E. Über die Blutzuckersenkende Wirkung des Kallikreins (Padutins). [The hypoglicemic effects of Kallikreins (Padutins)]. Klin Wochenschr 1932;11:846-849. German.

8. Dietze G, Wicklmayr M. [Effect of bradykinin on muscular glucose uptake in man]. Klin Wochenschr. 1977;55:357-358. German.

9. Dietze GJ, Wicklmayr M, Rett K, Jacob S, Henriksen EJ. Potential role of bradykinin in forearm muscle metabolism in humans. Diabetes. 1996;45 Suppl 1:S110-S114.

10. Isami S, Kishikawa H, Araki E, et al. Bradykinin enhances GLUT4 translocation through the increase of insulin receptor tyrosine kinase in primary adipocytes: evidence that bradykinin stimulates the insulin signalling pathway. Diabetologia. 1996;39:412-420.

11. Beard KM, Lu H, Ho K, Fantus IG. Bradykinin augments insulinstimulated glucose transport in rat adipocytes via endothelial nitric oxide synthase-mediated inhibition of Jun NH2-terminal kinase. Diabetes. 2006;55:2678-2687.

12. Zuccollo A, Navarro M, Frontera M, Cueva F, Carattino M, Catanzaro OL. The involvement of kallikrein-kinin system in diabetes type I (insulitis). Immunopharmacology. 1999;45:69-74.

13. Araujo RC, Mori MA, Merino VF, et al. Role of the kinin B1 receptor in insulin homeostasis and pancreatic islet function. Biol Chem. 2006;387:431-436.

14. Mori MA, Araujo RC, Pesquero JB. Kinin B1 receptor stimulation modulates leptin homeostasis. Evidence for an insulin-dependent mechanism. Int Immunopharmacol. 2008;8:242-246.

15. Fonseca RG, Sales VM, Ropelle E, et al. Lack of kinin B(1) receptor potentiates leptin action in the liver. J Mol Med (Berl). 2013;91:851-860.

16. Mori MA, Araújo RC, Reis FC, et al. Kinin B1 receptor deficiency leads to leptin hypersensitivity and resistance to obesity. Diabetes. 2008;57:1491-1500.

17. Mori MA, Sales VM, Motta FL, et al. Kinin B1 receptor in adipocytes regulates glucose tolerance and predisposition to obesity. PLoS One. 2012; 7:e44782.

18. Dias JP, Talbot S, Senecal J, Carayon P, Couture R. Kinin B1 receptor enhances the oxidative stress in a rat model of insulin resistance: outcome in hypertension, allodynia and metabolic complications. PLoS One. 2010;5:e12622.

19. Dias JP, Couture R. Blockade of kinin B(1) receptor reverses plasma fatty acids composition changes and body and tissue fat gain in a rat model of insulin resistance. Diabetes Obes Metab. 2012;14:244-253.

20. Duka I, Kintsurashvili E, Gavras I, Johns C, Bresnahan M, Gavras H. Vasoactive potential of the $\mathrm{b}(1)$ bradykinin receptor in normotension and hypertension. Circ Res. 2001;88:275-281.

21. Rodrigues ES, Silva RF, Martin RP, et al. Evidence that kinin B2 receptor expression is upregulated by endothelial overexpression of $\mathrm{B} 1$ receptors. Peptides. 2013;42:1-7.
22. Truett GE, Heeger P, Mynatt RL, Truett AA, Walker JA, Warman ML. Preparation of PCR-quality mouse genomic DNA with hot sodium hydroxide and tris (HotSHOT). Biotechniques. 2000;29:52-54.

23. Cayla C, Todiras M, Iliescu R, et al. Mice deficient for both kinin receptors are normotensive and protected from endotoxin-induced hypotension. FASEB J. 2007;21:1689-1698.

24. Torres HA, Louise Motta F, Sales VM, et al. Kinin B1 receptor gene ablation affects hypothalamic CART production. Biol Chem. 2013;394: 901-908.

25. Heijboer AC, Voshol PJ, Donga E, et al. High fat diet induced hepatic insulin resistance is not related to changes in hypothalamic mRNA expression of NPY, AgRP, POMC and CART in mice. Peptides. 2005;26:2554-2558

26. Wallingford N, Perroud B, Gao Q, et al. Prolylcarboxypeptidase regulates food intake by inactivating alpha-MSH in rodents. $J$ Clin Invest. 2009;119:2291-2303.

27. Fan W, Boston BA, Kesterson RA, Hruby VJ, Cone RD. Role of melanocortinergic neurons in feeding and the agouti obesity syndrome. Nature. 1997;385:165-168.

28. Schweitzer GG, Castorena CM, Hamada T, Funai K, Arias EB, Cartee GD. The B2 receptor of bradykinin is not essential for the postexercise increase in glucose uptake by insulin-stimulated mouse skeletal muscle. Physiol Res. 2011;60:511-519.

29. Duka I, Shenouda S, Johns C, Kintsurashvili E, Gavras I, Gavras H. Role of the $\mathrm{B}(2)$ receptor of bradykinin in insulin sensitivity. Hypertension. 2001;38:1355-1360.

30. Jaffa MA, Kobeissy F, Al Hariri M, et al. Global renal gene expression profiling analysis in B2-kinin receptor null mice: impact of diabetes. PLoS One. 2012;7:e44714.

31. Pesquero JB, Araujo RC, Heppenstall PA, et al. Hypoalgesia and altered inflammatory responses in mice lacking kinin B1 receptors. Proc Natl Acad Sci U S A. 2000;97:8140-8145.

32. Cunha TM, Verri WA Jr, Fukada SY, et al. TNF-alpha and IL-1beta mediate inflammatory hypernociception in mice triggered by B1 but not B2 kinin receptor. Eur J Pharmacol. 2007;573:221-229.

33. Gobel K, Pankratz S, Schneider-Hohendorf T, et al. Blockade of the kinin receptor B1 protects from autoimmune CNS disease by reducing leukocyte trafficking. J Autoimmun. 2011;36:106-114.

34. Kern PA, Saghizadeh M, Ong JM, Bosch RJ, Deem R, Simsolo RB. The expression of tumor necrosis factor in human adipose tissue. Regulation by obesity, weight loss, and relationship to lipoprotein lipase. J Clin Invest. 1995;95:2111-2119.

35. Saghizadeh M, Ong JM, Garvey WT, Henry RR, Kern PA. The expression of TNF alpha by human muscle. Relationship to insulin resistance. J Clin Invest. 1996;97:1111-1116.

36. Pannacciulli N, Cantatore FP, Minenna A, Bellacicco M, Giorgino R, De Pergola G. C-reactive protein is independently associated with total body fat, central fat, and insulin resistance in adult women. Int $J$ Obes Relat Metab Disord. 2001;25:1416-1420.

Diabetes, Metabolic Syndrome and Obesity: Targets and Therapy

Dovepress

\section{Publish your work in this journal}

Diabetes, Metabolic Syndrome and Obesity: Targets and Therapy is an international, peer-reviewed open-access journal committed to the rapid publication of the latest laboratory and clinical findings in the fields of diabetes, metabolic syndrome and obesity research Original research, review, case reports, hypothesis formation, expert opinion and commentaries are all considered for publication. The manuscript management system is completely online and includes a very quick and fair peer-review system, which is all easy to use. Visit http://www.dovepress.com/testimonials.php to read real quotes from published authors. 